\title{
RESPOSTAS PRODUTIVAS DO ALHO A DIFERENTES DENSIDADES DE PLANTAS E PESO DE BULBILHOS-SEMENTE
}

\author{
Yield response on garlic to differents plants densities and weight of seed clove
}

\author{
Marie Yamamoto Reghin ${ }^{1}$, Rosana Fernandes Otto ${ }^{1}$, Jeferson Zagonel ${ }^{1}$, \\ Maristella Dalla Pria ${ }^{1}$, Jhony Van Der Vinne ${ }^{2}$
}

\section{RESUMO}

Este experimento foi conduzido em Ponta Grossa (PR), localizada à altitude de $880 \mathrm{~m}$. O delineamento experimental foi o de blocos casualizados com quatro repetições; os tratamentos foram distribuídos em fatorial 2 x 4, sendo 2 pesos de bulbilhos-sementes $\left(\mathrm{P} 1=3,0-3,5 \mathrm{~g}\right.$ e P2 = 2,0 - 2,9 g) e 4 densidades de plantas $\mathrm{m}^{-2}(33,3,50,0,66,6$ e 100). Para obter essas densidades, trabalhou-se com o arranjo de plantas em fileiras simples e fileiras duplas. Nas simples, usaram-se quatro fileiras dispostas no sentido longitudinal do canteiro com 1,20 m de largura, no espaçamento de $0,30 \mathrm{~m}$ entre fileiras e 0,10 e $0,05 \mathrm{~m}$ entre plantas, obtendo-se 40 e 80 plantas $\mathrm{m}^{-2}$, respectivamente. Nas fileiras duplas, usaram-se três linhas duplas espaçadas 0,30 $\mathrm{m}$ entre si e, dentro da fileira, 0,10 e $0,05 \mathrm{~m}$, respectivamente, obtendo-se densidades de 60 e 120 plantas $\mathrm{m}^{-2}$. Os bulbossemente da cultivar Roxo Pérola de Caçador foram vernalizados por 40 dias a $4{ }^{\circ} \mathrm{C}$ antes do plantio. Após a vernalização, os bulbos foram debulhados e separados por peso. O plantio foi realizado em 14/05/2002, usando-se marcadores de madeira para os diferentes arranjos de plantas. Após a colheita, realizada em 03/10/2002, fez-se a cura e, posteriormente, a toalete. Avaliouse a produção de bulbos por $\mathrm{m}^{-2}$ classificando-os com pseudoperfilhamento, e em diferentes classes, de acordo com diâmetro. Os dados relativos aos pesos dos bulbilhos-sementes foram submetidos à análise fatorial e os de densidades, à regressão polinomial. Observou-se que os pesos de bulbilhos-semente utilizados não promoveram respostas produtivas significativas, exceto na característica de pseudoperfilhamento, com maior ocorrência quando se usaram bulbilhos-semente P2. Essa característica, em relação à densidade, tanto em P1 como para P2, apresentou resposta linear decrescente, de acordo com o aumento da densidade de plantas. Além disso, a densidade de plantas foi um fator decisivo no rendimento da produção tanto em relação ao volume quanto ao tamanho do bulbo produzido. Tanto para P1 como para P2, com o aumento da densidade de plantas, de 33,3 para 100 plantas $\mathrm{m}^{-2}$, houve acréscimo linear no volume de produção, de $1,28 \mathrm{~kg} \mathrm{~m}^{-2}$ para 2,94 kg m $\mathrm{kg} \mathrm{P}^{-2}$ e de 1,21 para $2,90 \mathrm{~kg} \mathrm{~m}^{-2}$, em P2, respectivamente. No entanto, com o aumento da produção total, ocorreu decréscimo no tamanho do bulbo produzido. Quando se classificaram os bulbos nas diferentes classes, observou-se efeito significativo somente para P1. A obtenção de rendimento de bulbos de maior valor comercial em P1, como as da classe $6(>47<55 \mathrm{~mm}$ ) em valor acima de $45 \%$ foi observada na densidade de 40 plantas $\mathrm{m}^{-2}$.

Termos para indexação: Allium sativum, arranjo populacional, bulbilho-semente, fileiras simples, fileiras duplas.

\begin{abstract}
The experiment was carried out in Ponta Grossa (PR), located in a altitude of $880 \mathrm{~m}$. The experimental design was a randomized blocks with four replications. Treatments arranged in a factorial scheme $2 \times 4$, resulted from the combination of two seed clove weight $(\mathrm{W} 1=3,0-3,5 \mathrm{~g}$ and $\mathrm{W} 2=2,0-2,9 \mathrm{~g})$ and four plants densities $\mathrm{m}^{-2}(33,3,50,0,66,6$ and 100). To obtain these densities, it was arranged plants in simple and double rows. On the simple row plants arrangement had four rows in longitudinal direction of the bed having $1,20 \mathrm{~m}$ width spaced 0,30 between rows and 0,10 and $0,05 \mathrm{~m}$ between plants, obtaining 33,3 and 66,6 plants $\mathrm{m}^{-2}$, respectively. On double one it was used three double rows spaced among them with $0,30 \mathrm{~m}$ and within row, 0,10 and $0,05 \mathrm{~m}$, respectively to obtain densities of 50 and 100 plants $\mathrm{m}^{-2}$. Seed bulbs of cultivar Roxo Pérola de Caçador were vernalized at $4^{\circ} \mathrm{C} / 40$ days before planting. After vernalization treatment the bulbs were thrashed and the bulbils separated by weight. The planting was at 14/05/2002, using plants arrangement in simple and double rows. Seed clove weight did not promote difference on yield response, except to characteristic of bulb secondary growth, being superior the occurrence on W2 compared to W1. In relation to plant densities, both on W1 and W2, it was observed linear response and it decreased in according of the increase on plant density. Besides, plant densities were effective on yield even in relation to total bulbs per area and
\end{abstract}

(Recebido para publicação em 26 de maio de 2003 e aprovado em 15 de agosto de 2003)

\footnotetext{
1. Doutores, Professores Adjunto do Departamento de Fitotecnia e Fitossanidade. Universidade Estadual de Ponta Grossa. Av. Carlos Cavalcanti, 4748 - 84030-900 - Ponta Grossa, PR, freghin@convoy.com.br

2. Bolsista de Iniciação Científica, acadêmico do $5^{\circ}$ ano do curso de Agronomia/UEPG.
} 
also considering bulb size. Both W1 and W2, increasing plant densities, from 33,3 to 100 plantas $/ \mathrm{m}^{2}$, it was observed linear response, from 1,28 to $2,94 \mathrm{~kg} \mathrm{~m}^{-2}$ to $\mathrm{W} 1$ and 1,21 to $2,90 \mathrm{~kg} \mathrm{~m}^{-2}$ to $\mathrm{W} 2$, respectively. The increasing of plants densities promoted higher yield however it was also observed decreasing on bulb size. When bulbs were classified into differents classes it was observed difference only when W1 was used. In order to obtain bulbs of higher value commercial in W1, as class 6 (> 47 $<55 \mathrm{~mm}$ ) higher than $45 \%$, this result was observed from density of 40 plants $\mathrm{m}^{-2}$.

Index terms: Allium sativum, plants arrangement, garlic seed clove, simple row, double row.

\section{INTRODUÇÃO}

Vários fatores, entre eles o peso do bulbilhosemente e o espaçamento, devem ser manejados de forma a propiciar máximo rendimento na cultura do alho (Allium sativum L.). De acordo com Lammerink (1988), os produtores devem procurar plantar bulbilhos no mínimo, da classe 3 , ou ao redor de $2,0 \mathrm{~g}$ para as cultivares de alto potencial produtivo; para cada grama de aumento nos bulbilhos plantados das cultivares Marlborough e Printanor, a produção de bulbos aumentou de 1,2 a 1,4 $\mathrm{t} \mathrm{ha}^{-1}$. Mueller e Biasi (1993) obtiveram maiores retornos econômicos com o emprego de bulbilhos maiores. Na prática, a definição do tamanho ou peso do bulbilho a ser utilizado depende principalmente do espaçamento, da cultivar, da forma de plantio e do custo da semente. Em geral, utilizando-se espaçamentos maiores, obtêm-se maior tamanho de bulbo e menor produção comercial por área. Kamitsuji (1995) observou que a produção aumenta com o aumento do tamanho de bulbo e do bulbilho, assim como a frequiência de bulbos das classes 5 e 6 . Dessa forma, bulbos e bulbilhos maiores favorecem a formação de bulbos com melhor crescimento e maior peso médio. Segundo Ohm e Srivastawa (1977), acréscimos na altura de plantas, diâmetro do pseudocaule, número de folhas por planta e diâmetro do bulbo são vantagens que se conseguem empregando espaçamentos maiores. Ao contrário, a utilização de espaçamentos reduzidos propicia normalmente menor tamanho de bulbos e maior produção por área (MUELLER e BIASI, 1982).

A maioria das referências sobre espaçamento para a cultura do alho indicam, como usuais, os limites de 20 a $40 \mathrm{~cm}$ entre linhas por 7,5 a $15 \mathrm{~cm}$ entre plantas na linha (SATURNINO et al., 1976; MUELLER e BIASI, 1982; GARCIA et al., 1984; GASTAUD e CARING, 1985). Em Minas Gerais, os produtores utilizam canteiros de $80 \mathrm{~cm}$ de largura e plantam três fileiras de plantas por canteiro, com uma população final de 300.000 plantas por hectare (SATURNINO et al., 1976). Em Santa Catarina, na maioria das áreas são utilizados canteiros com fileiras longitudinais em nú- mero de 4 a 5 , no espaçamento $25 \times 8 \mathrm{~cm}$; esse sistema proporciona populações de 250.000 a 370.000 plantas por hectare, dependendo da área perdida entre canteiros (LUCINI e CHONAN, 1986). Já no Rio Grande do Sul, é comum a sistematização do terreno em canteiro. Esses têm dimensões de aproximadamente 1,20 m de largura entre os centros dos sulcos de drenagem e utilizam-se 3 a 4 fileiras de plantas sobre a largura útil de cada canteiro, obtendo-se populações de 273.000 a 363.000 plantas por hectare (GARCIA et al., 1984). No cultivo convencional do alho, é comum dispor as plantas no canteiro em fileiras simples. A sistematização da área de cultivo em canteiros faz com que haja perda significativa de área útil, ocorrendo necessidade de máximo aproveitamento dessa área. Uma das formas é dispor a largura do canteiro de 1,20 m com arranjos de plantas em fileiras duplas, desde que as fileiras duplas suportem o uso de espaçamentos mais estreitos entre si e dentro da linha. Dessa forma, poderá ser duplicada ou triplicada a população convencionalmente usada. Por outro lado, não se têm observado relatos de pesquisa com utilização de fileiras duplas. Como o plantio se procede com órgão vegetativo e, na maioria das vezes, de forma manual, é possível o manejo com diferentes arranjos de plantas e disposição de plantas em fileiras simples e em fileiras duplas.

Com o presente trabalho objetivou-se avaliar respostas produtivas de dois pesos de bulbilhos-semente arranjados em diferentes densidades de plantas, no cultivo do alho.

\section{MATERIAL E MÉTODOS}

O experimento foi conduzido em Ponta Grossa (PR), localizada a altitude de $880 \mathrm{~m}$ e em solo do tipo CAMBISSOLO HÁPLICO Tb Distrófico, de textura argilosa. O delineamento experimental foi o de blocos casualizados, com quatro repetições; os tratamentos foram distribuídos segundo esquema fatorial $2 \times 4$, com dois pesos de bulbilhos-semente ( $\mathrm{P} 1=3,0-3,5 \mathrm{~g}$ e $\mathrm{P} 2=2,0-2,9 \mathrm{~g})$ e quatro densidade de plantas $\mathrm{m}^{-2}$ $(33,3,50,0,66,6$ e 100). Os canteiros foram preparados com enxada rotativa, tendo largura de $1,20 \mathrm{~m}$. A adu- 
bação química foi realizada segundo recomendações da CFSEMG (1999), uma semana antes do plantio, com termofosfato $\left(800 \mathrm{~kg} \mathrm{ha}^{-1}\right)$ e cloreto de potássio $(66,7 \mathrm{~kg}$ $\left.\mathrm{ha}^{-1}\right)$. Em cobertura, uma semana após o início da diferenciação dos bulbilhos (aos 103 dias do plantio), fez-se adubação com nitrocálcio (100 kg ha ${ }^{-1}$ ). A área foi mantida com irrigação por gotejamento. Os bulbos-semente da classe 3 da cultivar Roxo Pérola de Caçador foram vernalizados por 40 dias a $4^{\circ} \mathrm{C}$. Em seguida, foram debulhados e separados por peso utilizando-se balança. $\mathrm{O}$ plantio foi realizado em 14/05/2002, usando fileiras simples, espaçadas de $0,30 \mathrm{~m}$ entre si e com 0,05 e $0,10 \mathrm{~m}$ entre plantas para se ter as densidades de 33,3 e 66,6 plantas $\mathrm{m}^{-2}$, respectivamente. As três fileiras duplas tiveram $0,10 \mathrm{~m}$ de distância entre si e, entre as duplas, 0,30 m. Entre plantas, 0,05 e $0,10 \mathrm{~m}$ para se obter 50 e 100 plantas $\mathrm{m}^{-2}$. A colheita foi realizada em 14/10/2002, numa área útil de $1 \mathrm{~m}^{2}$. Após a cura, procedeu-se à toalete, sendo eliminadas folhas e raízes dos bulbos. Avaliaram-se a produção total em peso e o peso médio do bulbo. Posteriormente, fez-se a separação dos bulbos com pseudoperfilhamento e classificação segundo diâmetro transversal em classes, baseada na circular 50/81 da Comissão Técnica de Normas e Padrões do Ministério da Agricultura: 1 (menor que $25 \mathrm{~mm}), 2$ (>25 $<32 \mathrm{~mm}$ ), 3 (>32<37 mm), 4 (>37<42mm), 5 (>42<47 $\mathrm{mm}), 6(>47<55 \mathrm{~mm}$ ) e 7 (maior que $55 \mathrm{~mm}$ ). Os resultados obtidos para as diferentes características foram submetidos à análise de variância. Os dados de peso foram comparados pelo teste de Tukey (5\%), e os de densidades, submetidos à análise de regressão e teste $\mathrm{F}$ $(5 \%)$.

\section{RESULTADOS E DISCUSSÃO}

Não foi observado efeito significativo da interação, nem diferenças significativas devidas ao peso do bulbilho-semente para as características de altura e do número de folhas, assim como para as características de produção (Tabela 1). Embora Lucini et al. (1983) tenham verificado aumento de produtividade de bulbos conforme se aumentava o peso dos bulbilhos-semente utilizados $(0,83 ; 1,46 ; 2,35$ e $3,65 \mathrm{~g})$, os resultados deste experimento foram diferentes, provavelmente pelo fato de a amplitude de variação entre os pesos de bulbilhos testados ter sido relativamente pequena $(2,0$ a $3,5 \mathrm{~g})$.

$\mathrm{O}$ peso do bulbilho-semente promoveu, no entanto, resposta diferenciada para ocorrência de pseudoperfilhamento (Tabela 1).

Quando se usou bulbilho-semente de menor peso $(\mathrm{P} 2=2,0-2,9 \mathrm{~g})$, houve maior porcentagem de bulbos com pseudoperfilhamento, comparado a P1 (3,0 - 3,5 g), resultado semelhante ao observado por Kamitsuji (1995). Esse é um dado importante, visto que essa ocorrência é uma das mais temidas pelos produtores. $\mathrm{O}$ pseudoperfilhamento é um distúrbio genéticofisiológico que deprecia a qualidade de bulbos e reduz sua capacidade de conservação. Tem sido associado, entre outros fatores, a níveis elevados de $\mathrm{N}$ e de água no solo, especialmente no estádio final da cultura (VASCONCELOS et al., 1971; SOUZA e CASALI, 1986; COSTA et al., 1993). Provavelmente, em cultivar suscetível, como a Roxo Pérola de Caçador, o uso de bulbilhos-semente de menor peso predispõe à ocorrência de pseudoperfilhamento, principalmente se se tratar de regiões como Ponta Grossa, com alta incidência de precipitação pluvial no período que coincide com o final de ciclo da cultura (Figura 1).

A ocorrência de pseudoperfilhamento para P1 e P2 foi semelhante para as diferentes densidades de plantio, com resposta linear decrescente (Figura 2) em ambos os casos.

TABELA 1 - Produção $\left(\mathrm{kg} \mathrm{m}^{-2}\right)$, peso médio do bulbo (g), pseudoperfilhamento (\%) e rendimento comercial (\%) de bulbos de alho nas diferentes classes, em função do peso do bulbilhos-semente. Ponta Grossa, PR. 2002.

\begin{tabular}{|c|c|c|c|c|c|c|c|}
\hline \multirow{2}{*}{$\begin{array}{l}\text { Peso do } \\
\text { bulbilho }\end{array}$} & \multirow{2}{*}{$\begin{array}{c}\text { Produção } \\
\left(\mathrm{kg} \mathrm{m}^{-2}\right)\end{array}$} & \multirow{2}{*}{$\begin{array}{l}\text { Peso Médio do } \\
\text { bulbo (g) }\end{array}$} & \multirow{2}{*}{$\begin{array}{c}\text { Pseudoperfilhamento } \\
(\%)\end{array}$} & \multicolumn{4}{|c|}{ Rendimento comercial $(\%)^{1}$} \\
\hline & & & & Tipo 7 & Tipo 6 & Tipo 5 & Tipo 4 \\
\hline $\mathrm{P} 1$ & $1,07 a^{*}$ & $28,01 \mathrm{a}^{*}$ & $12,68^{*} \mathrm{~b}$ & $12,97 \mathrm{a}^{*}$ & $34,86 a^{*}$ & $34,76 a^{*}$ & $19,39 \mathrm{a}^{*}$ \\
\hline $\mathrm{P} 2$ & $1,57 \mathrm{a}$ & $25,78 \mathrm{a}$ & $19,91 \mathrm{a}$ & $9,97 \mathrm{a}$ & $41,76 \mathrm{a}$ & $31,39 \mathrm{a}$ & $23,69 \mathrm{a}$ \\
\hline C.V (\%) & 14,32 & 11,83 & 28,38 & 41,83 & 39,31 & 37,58 & 37,21 \\
\hline
\end{tabular}

${ }^{1}$ Valores transformados para arc sen $(\mathbf{x}+\mathbf{0 , 5})$.

*Médias seguidas da mesma letra na coluna não diferem significativamente entre si no a $5 \%$ de probabilidade pelo teste de Tukey. 


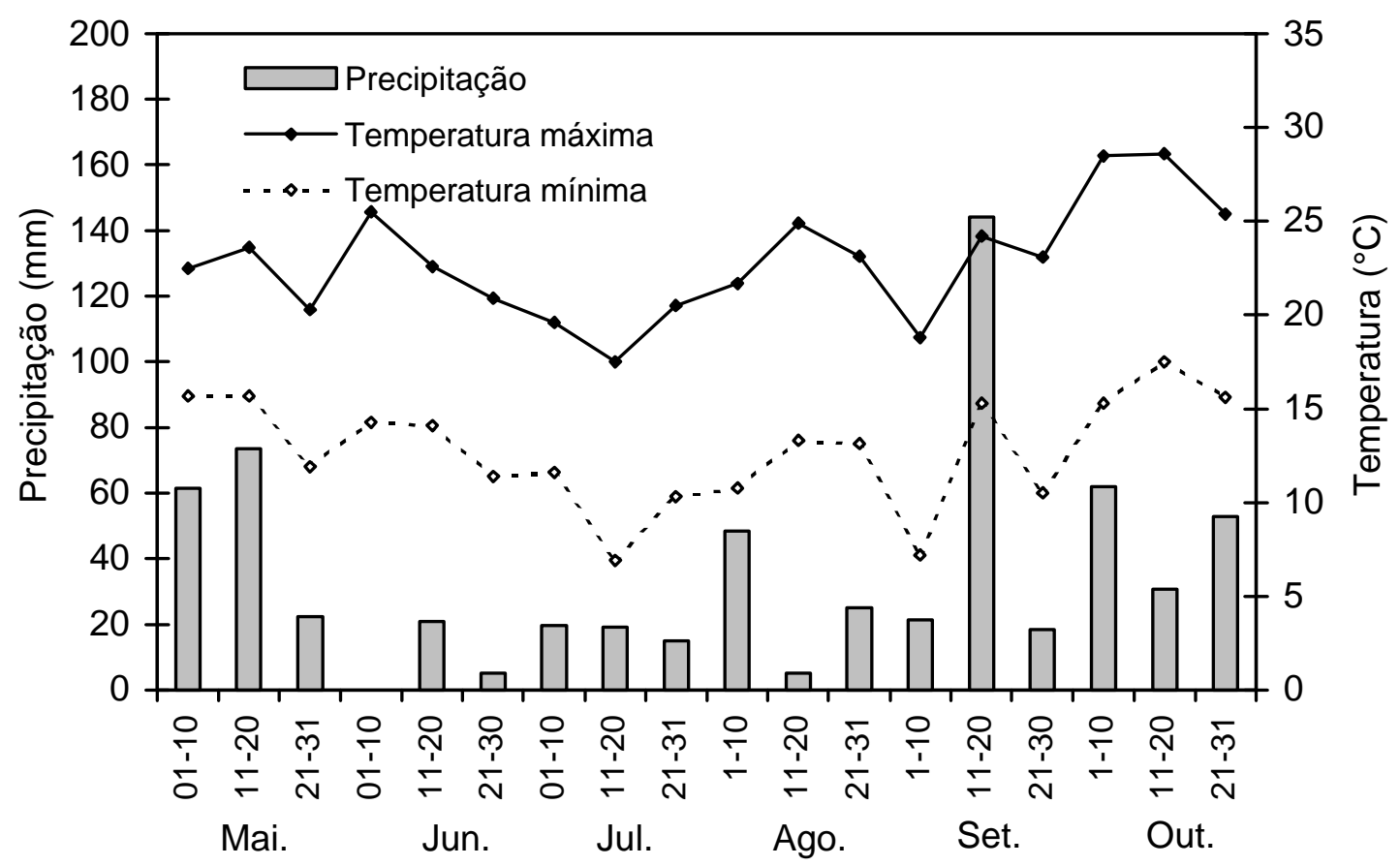

FIGURA 1 - Temperaturas máximas e mínimas $\left({ }^{\circ} \mathrm{C}\right)$ e precipitação $(\mathrm{mm})$ por decêndio no período de maio a outubro/2002. *Dados obtidos via Banco de Dados Agrometeorológicos do IAPAR - Ponta Grossa (PR).

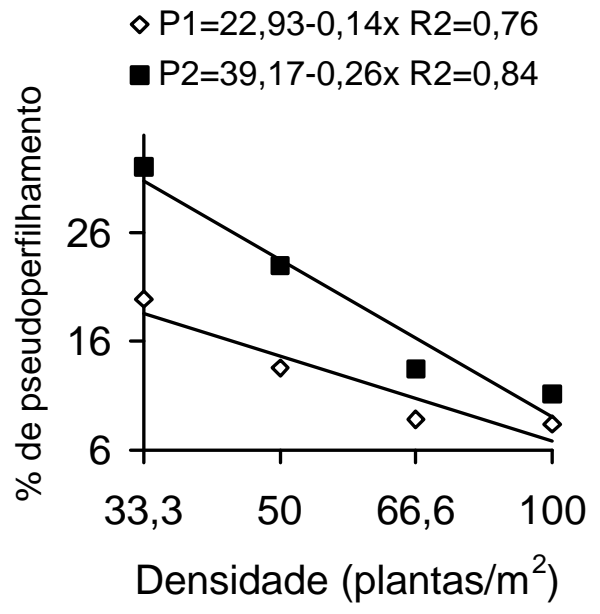

FIGURA 2 - Porcentagem de pseudoperfilhamento de alho em diferentes densidades de plantio e pesos de bulbilhos-sementes. Ponta Grossa, PR. 2002. 
À medida que se aumentou a densidade de plantio, houve decréscimo na porcentagem de pseudoperfilhamento. Provavelmente as plantas submetidas a uma maior densidade populacional, sujeitas à maior concorrência por espaço, luz, nutrição e umidade, formam bulbos menores, os quais têm menor predisposição ao pseudoperfilhamento. É importante salientar que os bulbos com pseudoperfilhamento não chegaram a romper totalmente a película de proteção dos bulbos, de forma que os bulbilhos raramente ficaram expostos, provavelmente por esse fato ter ocorrido no final de ciclo da cultura.

Considerando as diferentes densidades utilizadas, houve efeito significativo para todas as características avaliadas (Figuras 3, 4 e 5). Com relação à produção por área, houve resposta linear crescente, isto é, com o aumento da densidade de plantas de 33,3 para 100 plantas $\mathrm{m}^{-2}$, houve aumento da produção de bulbos, independentemente do peso do bulbilho utilizado (Figura 3 A). Em P1, o aumento foi de 1,28 para 2,94 $\mathrm{kg} \mathrm{m}^{-2}$, e em $\mathrm{P} 2$, de 1,21 para $2,90 \mathrm{~kg} \mathrm{~m}^{-2}$, representando um acréscimo médio de $1,68 \mathrm{~kg} \mathrm{~m}^{-2}$, aumento altamente representativo em termos de volume de produção. Ao contrário, com relação ao peso médio do bulbo, ocorreu uma diminuição desse. A resposta foi linear decrescente. À medida que se aumentou a densidade de plantas, houve diminuição do tamanho do bulbo (Figura 3B), concordando com os resultados obtidos por Mueller e Biasi (1982) e Mueller et al. (1998). Portanto, ao se aumentar a produção pelo aumento da densidade de plantas, não se tem a mesma resposta em relação à qualidade do bulbo, ocorrendo diminuição do seu peso. É possível trabalhar com densidades maiores, fazendo arranjos de plantas em fileiras duplas ou diminuindo o espaçamento entre plantas de 0,10 para $0,05 \mathrm{~m}$ para atingir alta produtividade de bulbos/área, o que seria interessante para campo de sementes. A definição da densidade de plantio vai depender, dentre outros fatores, da finalidade da produção, da quantidade de semente disponível e do custo da mesma. Garcia et al. (1992) também concluíram que ocorre aumento da produtividade com alterações nos níveis do fator espaçamento entre plantas. Quando se separaram os bulbos por classe, ficou evidente que a densidade de plantas é o fator de influência sobre o tamanho do bulbo produzido. Essa classificação é a mais importante para o produtor, pois quanto maior o percentual de bulbos de classes superiores, maior será sua rentabilidade econômica. À medida que houve aumento da densidade de plantas, ocorreu diminuição do rendimento de bulbos de classes superiores, ou seja, da 7 e 6, apresentando resposta linear decrescente (Figuras 4 A e 4 B). Esse mesmo comportamento foi relatado por Mueller et al. (1998). Por sua vez, no rendimento de bulbos da classe 5, houve resposta quadrática com ponto de máximo $(44,1 \%)$ na densidade de 80 plantas $\mathrm{m}^{-2}$ (Figura $5 \mathrm{~A}$ ). E para o rendimento dos bulbos da classe 4 , observou-se comportamento linear crescente em função da densidade de plantas, ou seja, nas densidades maiores (66,6 e 100 plantas $\mathrm{m}^{-2}$ ), ocorreram maiores rendimentos de bulbos de tamanho menor (Figura 5 B). Deve ser salientado que o efeito da densidade no rendimento de bulbos das diferentes classes somente foi significativo quando se usaram bulbilhos-semente do P1 ( 3,0 a 3,5 g), demonstrando que, em bulbilhos menores (2,0 a 2,9 g), qualquer uma das densidades usadas não promoveu diferença significativa na produção de bulbos de diferentes classes (Figuras $4 \mathrm{e}$ 5). Desse modo, em P2, o produtor poderá utilizar altas densidades, usando fileiras simples, com menor espaçamento entre plantas, ou seja, $0,5 \mathrm{~m}$, ou fileiras duplas, com 0,5 m entre plantas, com máximo aproveitamento da área e, portanto, alto rendimento/área. Deve ser salientado que não houve produção de bulbos das classes 2 e 1 , e os da classe 3 , em função do número reduzido (total de três), foram juntados aos da classe 4 .

Considerando os resultados obtidos e adicionado à realidade que o item alho-semente perfaz um total de $30 \%$ do custo de produção, na prática, se faz necessário o uso ajustado da densidade de plantas, de acordo com o peso de bulbilhos-sementes. No entanto, para o produtor interessado na obtenção de bulbos graúdos como os da classe 6 (> $47<55 \mathrm{~mm}$ ), usando sementes P1, em valor acima de $45 \%$, observou-se esse resultado na densidade de 40 plantas $\mathrm{m}^{-2}$. 

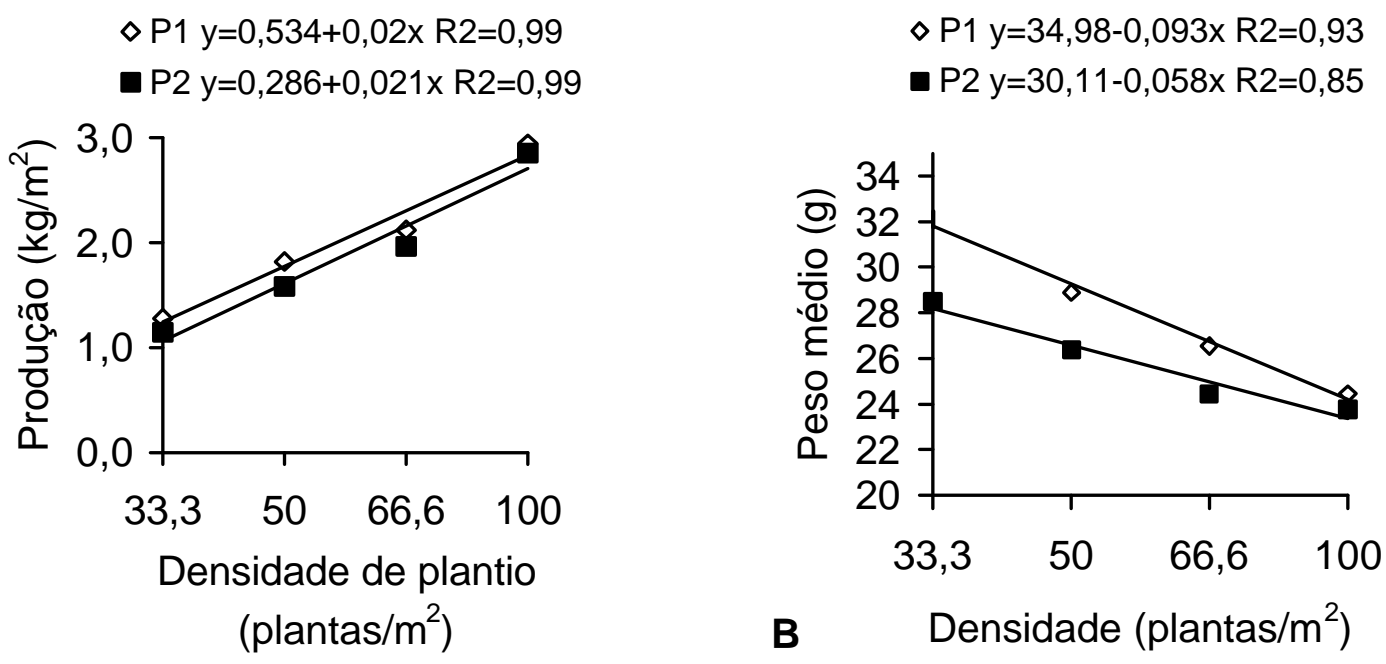

FIGURA 3 - Produção (A) e peso médio de bulbo (B) de alho em diferentes densidades de plantio e pesos de bulbilhos-semente. Ponta Grossa, PR. 2002.

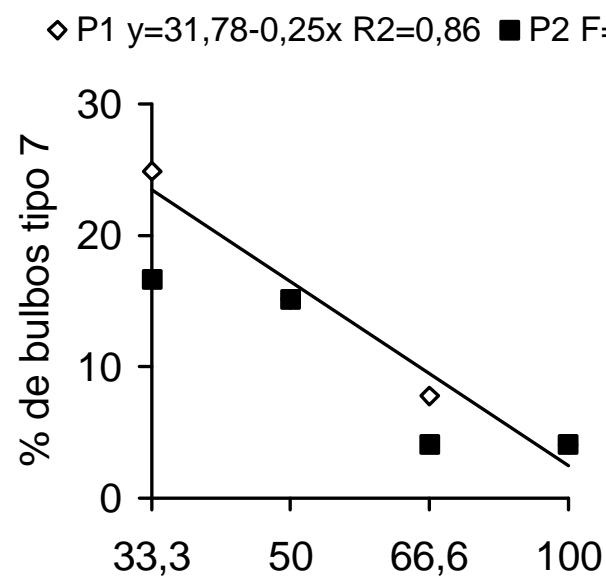

A Densidade (plantas $\left./ \mathrm{m}^{2}\right)$ $\diamond P 1 y=83,19-0,61 \times R 2=0,95 \square P 2 F=n . s$

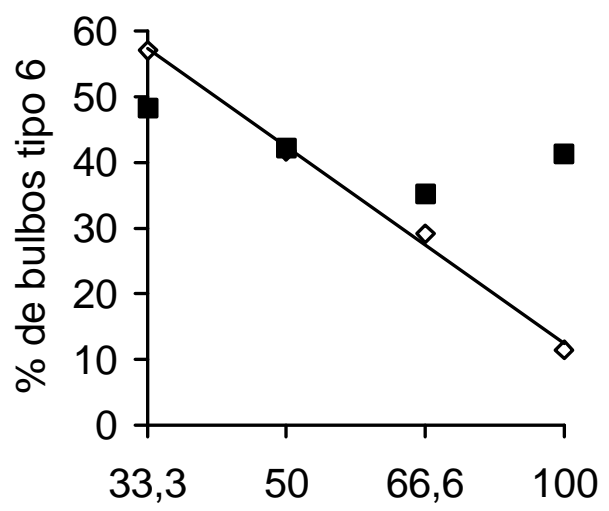

B Densidade (plantas $/ \mathrm{m}^{2}$ )

FIGURA 4 - Porcentagem de bulbos do tipo 7 (A) e 6 (B) em diferentes densidades de plantio e pesos de bulbilhos-sementes. Ponta Grossa, PR. 2002. 
I $\quad P 1 y=33,77+1,69 \times 0,009 \times 2 R 2=0,93$

- P2 F=n.s

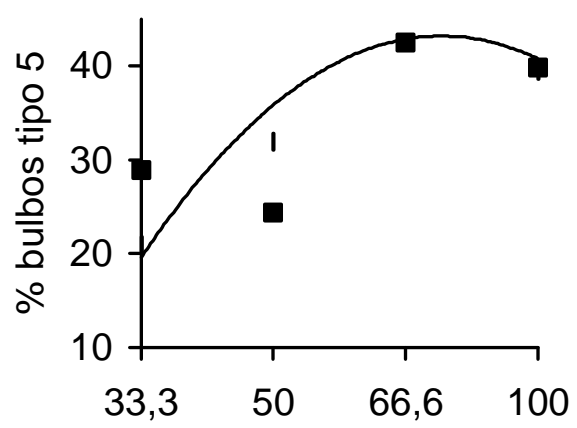

A Densidade $\left(\right.$ plantas $\left./ \mathrm{m}^{2}\right)$
I $\mathrm{P} 1 \mathrm{y}=23,65+0,57 \times \mathrm{R} 2=0,94 \boldsymbol{P} 2 \mathrm{~F}=\mathrm{n} . \mathrm{s}$

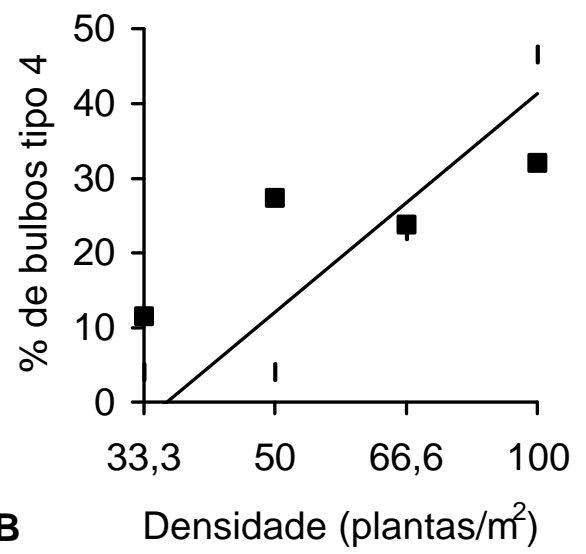

FIGURA 5 - Porcentagem de bulbos do tipo 5 (A) e 4 (B) de alho em diferentes densidades de plantio e tamanhos de bulbilhos-semente. Ponta Grossa, PR. 2002.

\section{REFERÊNCIAS BIBLIOGRÁFICAS}

COMISSÃO DE FERTILIDADE DO SOLO DO ESTADO DE MINAS GERAIS. Recomendações para o uso de corretivos e fertilizantes em Minas Gerais: $5^{\mathrm{a}}$ aproximação. Viçosa, 1999. 359 p.

COSTA, T. M. P.; SOUZA, R. J.; SILVA, A. M. Efeitos de diferentes lâminas de água e doses de nitrogênio sobre a cultura do alho (Allium sativum L. cv. Juréia). Ciência e Prática, Lavras, v. 17, n. 3, p. 239-246, 1993.

GARCIA, A.; MORAES, E. C.; MADAIL, J. C. M. A cultura do alho. Pelotas: EMBRAPA/CNPFT, 1984 76 p. (Circular Técnica, 8).

GARCIA, D. C.; BARNI, V.; DETTMANN, L. A. Influência da disposição das fileiras e espaçamento entre plantas no rendimento de alho. Ciência Rural, Santa Maria, v. 22, n. 3, p. 277-280, 1992.

GASTAUD, C. S.; CARING, L. de A. O. Ensaio de espaçamento na cultura do alho. In: REUNIÃO TÉCNICA ANUAL DE HORTALIÇAS, 1983, 1984. Porto Alegre. Ata... Porto Alegre: SEAGRI-IPAGRO, 1985. p. 412.

KAMITSUJI, M. K. Efeito do tamanho de bulbo, de bulbilho e da termoterapia sobre a produtividade de alho (Allium sativum L.) cv. Roxo Pérola de Caçador. 1995. 63 f. Dissertação (Mestrado em Horticultura) - Universidade Estadual Paulista. Faculdade de Ciências Agronômicas. Campus de Botucatu, Botucatu, 1995.
LAMMERINK, J. Better garlic yields through selection and seed clove grading. New Zealand Coomercial Grower, Wellington, v. 43, n. 3, p. 1617, 1988.

LUCINI, M. A.; CHONAN, T. Área experimental com fileiras duplas. Curitibanos: [s.n.], 1986. 5 p. Mimeografado.

LUCINI, M. A.; CHONAN, T.; BIASI, J.; MUELLER, S. Cultura do alho: efeito do peso do bulbilho-semente. In: CONGRESSO BRASILEIRO DE OLERICULTURA, 23., 1993, Rio de Janeiro, RJ. Resumos... Rio de Janeiro, RJ: SOB, 1983. p. 103.

MUELLER, S.; BIASI, J. Efeito do espaçamento de plantio do alho, sobre o rendimento e seus componentes. In: CONGRESSO BRASILEIRO DE OLERICULTURA, 1982, Vitória. Resumos... Vitória, SOB, 1982. p. 252.

MUELLER, S.; BIASI, J. Espaçamentos de plantio de alho relacionados a diferentes pesos de bulbilhos. In: CONGRESSO BRASILEIRO DE OLERICULTURA, 33., 1993, Brasília, DF. Horticultura Brasileira, Brasília, v. 11, n. 1, p. 85, 1993.

MUELLER, S.; KREUZ, C. L.; MONDARDO, M. Produtividade, qualidade e lucro em função de espaçamentos de plantio e pesos de bulbilhos-semente de alho. Agropecuária Catarinense, Florianópolis, v. 11, n. 1, p. 52-56, 1998. 
OHM, H.; SRIVASTAWA, R. P. Influence of the planting material and spacing on the growth yield of garlic. Indian Journal of Horticulture, New Delhi, v. 34, n. 2, p. 152-156, 1977.

SATURNINO, M. H.; MASCARENHAS, M. H. T.; FONTES, P. C. R. Uso de diferentes arranjos de plantas em dois tipos de canteiros de alho (Allium sativum L.). Revista de Olericultura, Campinas, v. 16, p. 41-44, 1976.
SOUZA, R. J.; CASALI, V. W. D. Pseudoperfilhamento: uma anormalidade genético-fisiológica em alho. Informe Agropecuário, Belo Horizonte, v. 12, n. 142, p. 36-41, 1986.

VASCONCELOS, E. F. C.; SCALOPI, E. J.; KLAR, A. A influência da irrigação e adubação nitrogenada na precocidade e "superbrotamento" da cultura do alho (Allium sativum L.). O Solo, Campinas, v. 63, n. 2, p. 15-19, 1971. 